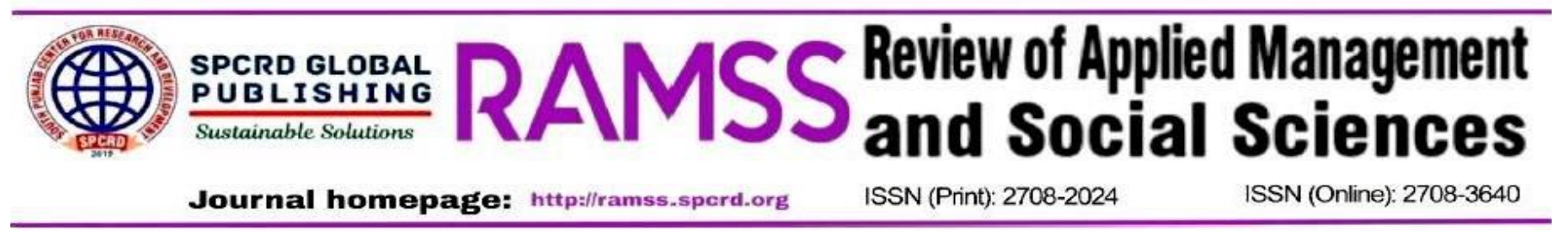

\title{
Impact of Institutional Investors Investment Decisions on the Pakistan Stock Exchange
}

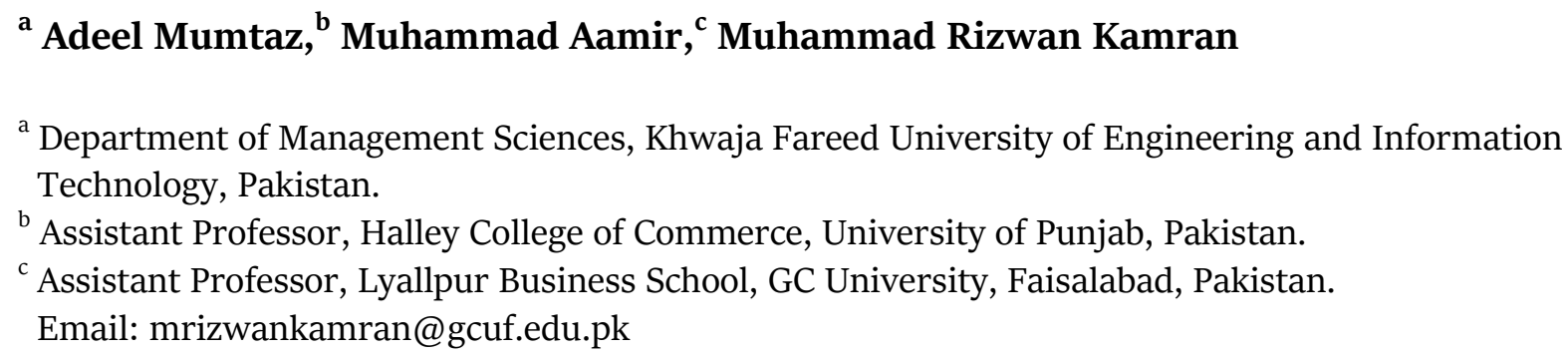

\begin{tabular}{l}
\hline ARTICLE DETAILS \\
\hline History: \\
Accepted 22 December 2021 \\
Available Online December 2021
\end{tabular}

Keywords:

Institutional Investors;

Behavioral Factors; Investment

Decision-Making

JEL Classification:

P33, D70,

\begin{abstract}
Institutional Investors play an important role in the stock price movement of stock markets of a country. The current study explores the factors Heuristic, Risk Aversion (RA), Day-to-day Experience (DTDE) \& Corporate Governance (CG) which significantly affect the Investment Decision-marking (IDM) in the Pakistan Stock Exchange. This study addresses this gap and delivers literature concerning the effect of CG \& DTDE on the Investment Decision-making (IDM). This study used 215 institutional investors, which are trading in the Pakistan Stock Exchange (PSX). This study used OLS for estimation of models. The findings revealed that DTDE and CG play a vital role in IDM in Pakistan.
\end{abstract}

DOI: $10.47067 /$ ramss.v4i4.202

(C) 2021 The authors. Published by SPCRD Global Publishing. This is an open-access article under the Creative Commons Attribution-

NonCommercial 4.0

Corresponding author's email address: mrizwankamran@gcuf.edu.pk

\section{Introduction}

IDM is the valuable phenomenon which influence as well as affected by many factors. For example, IDM has an influence on the firm-level outcome (Madaan, \& Singh,2019). Therefore, behavioral factors effect on the IDM of the investors, which invest in the stock exchange (Zahera, \& Bansal, 2018). Same as, psychological factors influence on the IDM in stock market (Sun,2020). So, scholars used combnined effect of all these factors on IDM is limited in Pakistan.

Firstly, DTDE play an important role in IDM. Ignore to paid attention to test this link empirically. Secondly, CG paly the crucial role in the IDM. This study suggests addressing these 
limitations in these ways. First, this study focuses on contribution of CG and DTDE. However, DTDE has a significant influence on IDM in the financial sector of Pakistan. For instance, Khalid, (2020) DTDE has significant influence on the IDM in the financial sector of Pakistan. Secondly, CG has significant effect on the IDM in the financial sector of Pakistan (Shahid, \& Abbas, 2019).

\section{Literature Review}

IDM is a very complicated process and it's not easy task at all. Portfolio investment is a secure investment based on rationality of institutional investors. The investment in several types of securities helps to avoid losses and make it compulsory to have some sure returns (Madaan, \& Singh, 2019; Markowitz, 1958).

\subsection{Investment Decision-Making}

Shareholders utilize all accessible information relating to making IDM. Shareholders use different techniques to collect significant evidence like assessment, meeting market information, TV plan, media etc. and then take a sensible decision (Cazilia \& Tahira, 2009). There are several factors having impact upon fund manager's IDM These factors are heuristic, RA behavior, DTDE, and CG. These elements are based upon psychology of human beings (Kahneman and Taversky, 1979). In spite of many sophisticated financial instruments like CAPM, Portfolio diversification and risk \& return, there are variations and volatility in stock prices. The inconsistent market behavior and sudden rise and fall in prices of stocks are evident that there are some other elements that cause to fluctuate the stock prices. These are factors having impact upon IDM (Subrahmanyaum, 2008).

\subsection{Heuristic}

Heuristic means decision-making process needs the expertise (Hunter, 2011). The fund manager of the organization has significant impact on IDM process. The investors have more focus on investment decision, when the level of heuristic enhanced (Kahneman \& Taversky, 1979). Shareholders are overconfidence in their individual capabilities, especially in parts where they have few basic desires and have some expertise (Gill, Khurshid, Mahmood, \& Ali, 2018). The effect on IDM by bias and overconfidence is due to heuristic (Belmi, Neale, Reiff, \& Ulfe, 2020). The earnings of investors estimated by fund manager are not relevant as compared to expectations of investors due to behavioral biases. Annual earnings of open-ended mutual funds were overestimated by fund manager.

$\mathbf{H}_{\mathbf{1}}$ : Heuristic has significant positive impact on $I D M$.

\subsection{Risk Aversion}

The capability of receiving risk if there is guarantee of some expected benefits and probabilities to increase shareholder's capital (Abani, Hary, Rious, \& Saguan, 2018). In different conditions of risk, investors show different attitude. RA behavior of investors indicate that there are sure gain expectations. The investor act as risk taker when there are expectation of losses concerning making investment decision (Kahneman \& Taversky, 1979). They tend to be risk opposed when there is sure return expectation. The selection of risk aversion attitude is much vital and important under some risky conditions like selection of risk under condition of ambiguity. Because in such condition the decision making can be confusing and definite harms can be bear, thus it is called important choice (Haile, Nillesen, \& Tirivayi, 2020). The risk bearing attitude and selection of risky attitude based on the original situation. The risk bearing and risk aversion attitude are selected by financial advisors after observing the conditions of the marketplaces.

$\mathbf{H}_{\mathbf{2}}$ : RA has significant positive impact on IDM. 


\subsection{Corporate Governance}

"The methods by which corporations are managed and organized, the whole accountability is on top administration" (Safdar A. Butt, 2012). The CG is heart of independence of audit team (Bolton, 2002). Organizational level CG is very important for financial advisors. Weak governance can increase the organizational expense and lead towards a loss. On other hand, good corporate governance can be helpful to attain the institutional objectives and cause to improve the managerial outcomes (Schleich, Gassmann, Meissner, \& Faure, 2019).

H3: CG has a positive impact on the IDM.

\subsection{Day-to-day Experience}

DTDE to explore and integrate new knowledge, is considered an important factor which effects the IDM. However, DTDE described by existing literature in many studies (Brown \& Ryan, 2003). Moreover, recent empirical studies which are conducted in other contexts have found a significant link between DTDE and IDM (Hertwig \& Erev, 2009; Rakow \& Newell, 2010). With this backdrop, DDE should have a positive impact on IDM. Hence, research scholar hypothesizes that:

H4: DTDE has a significant positive influence on IDM.

\section{Research Methodology}

The research methodology required to analyze the factors (Heuristics, RA, DTDE, and CG) which effect the investment decisions in financial sector of Pakistan. This study is applied research from outcome point of view and is descriptive-correlation research from methodology view. Datacollection instrument is questionnaires. The researcher used the adaptive questionnaires. The adopted questionnaire of heuristics from Waweru et al (2008). The adopted questionnaire for risk aversion, corporate governance and investment decision making form Mayfield (2008), Klapper and Love (2004) and Pasework and Rilay (2010) respectively.

Our targeted population is the financial segment of Pakistan in which financial managers of investment corporations, banks, insurance corporations and individual shareholders which invest in Pakistan stock exchange, both private and public sectors. But we use sample size of 215 financial managers involved in financial decisions. In this research, we used the Convenance sampling.

\section{Results and Analysis}

In this study, we analysis the factors (Heuristics, RA, DTDE and CG) which effect the IDM in financial sectors of Pakistan. The Descriptive statistics is given below.

\section{1 Descriptive Statistics}

Descriptive Statistics deliver the quantitative summary of all independent and dependent variables. 
Table 1: Descriptive Statistics

\begin{tabular}{|c|c|c|c|c|c|c|c|c|}
\hline Variables & $\mathbf{N}$ & $\begin{array}{l}25^{\text {th }} \\
\text { Percentile }\end{array}$ & Mean & Median & $\begin{array}{l}75^{\text {th }} \\
\text { Percentile }\end{array}$ & $\begin{array}{l}\text { St. } \\
\text { Deviation }\end{array}$ & Skewness & Kurtosis \\
\hline Heuristics & 215 & 3.429 & 3.689 & $3 \cdot 714$ & 4 & .582 & -1.126 & 1.953 \\
\hline DTDE & 215 & 3.533 & $3 \cdot 723$ & 3.867 & 4 & .474 & -1.560 & 4.040 \\
\hline RA & 215 & 3.500 & 3.689 & 3.750 & 4.250 & .662 & -1.070 & 1.650 \\
\hline CG & 215 & 3.533 & 3.723 & 3.867 & 4 & .474 & -1.560 & 4.040 \\
\hline IDM & 215 & 3.429 & 3.745 & 3.857 & 4.143 & .555 & -1.096 & 1.673 \\
\hline
\end{tabular}

Table 2 reports the descriptive statistics of the dataset used in this study.

Table 1 presents the descriptive statistics of the variables used in this research. IDM is used as dependent variable. Heuristics, RA, DTDE \& CG are the independent variables of the study. Furthermore, 215 questionnaires are used to conduct this research work.

\subsection{Correlation Analysis}

Correlation matrix is showing the relationship between all the variables. Tables show the correlation analysis of heuristics, RA, CG, and DTDE with IDM in financial sectors of Pakistan. The 215 samples are used for this analysis. All the variables significant at the sig value 0.01

Table 2: Correlation Matrix

\begin{tabular}{|l|l|l|l|l|l|}
\hline Variables & Heuristics & RA & DTDE & CG & IDM \\
\hline Heuristics & 1 & & & & \\
\hline RA & $.445^{* *}$ & 1 & & & \\
\hline DTDE & $.416^{* *}$ & $.426^{* *}$ & 1 & & \\
\hline CG & $.463^{* *}$ & $.445^{* *}$ & $.489^{* *}$ & 1 & \\
\hline IDM & $.388^{* *}$ & $.439^{* *}$ & $.396^{* *}$ & $.481^{* *}$ & 1 \\
\hline
\end{tabular}

**. Correlation is significant at the 0.01 level (2-tailed).

The table 2 shows the correlation coefficient between the independent and dependent variables which denote the relationship between variables. DTDE correlation value is the .416 Which shows the positive and significant relationship with IDM at the level of significant 0.01. Heuristics have value of correlations is the .388 which denote the significant and positive relationship with IDM at the level of 0.01 significant. Correlation value of CG is the .463 which depict the positive and significant associations with financial investment decisions at the level of significant 0.01. RA value of correlation is the .445 which tell us the positive and significant relationship with IDM with level of significant. The table 2 result shows that dependent variable is totally dependent on all the independent variables 


\subsubsection{Multiple Regression}

The multiple regression of dependent and independent variables. The multiple regression equation is given blew.

$$
I D M=b_{o}+b_{1} H+b_{2} R A+b_{3} D T D E+b_{4} C G+e
$$

Table: 3 Multiple Regression

\begin{tabular}{|c|c|c|c|c|c|c|c|}
\hline Constant & Heuristics & DTDE & RA & CG & $\mathrm{R}^{2}$ & F-Statistics & $\begin{array}{l}\text { Durbin- } \\
\text { Watson }\end{array}$ \\
\hline 1.104 & .145 & .120 & .201 & .259 & \multirow{4}{*}{$\cdot 312$} & \multirow{4}{*}{157.106} & \multirow{4}{*}{2.084} \\
\hline .153 & .032 & .036 & .031 & .046 & & & \\
\hline [7.237] & [3.169] & {$[3.854]$} & [5.352] & [6.662] & & & \\
\hline .000 & .000 & .002 & .000 & .000 & & & \\
\hline
\end{tabular}

a. Dependent Variable: IDM

b. Predictors: (Constant), Heuristics, CG, DTDE, RA,

The tables 3 shows the result of multiple regression model. The coefficient determination is .312 which indicates the accuracy of this research model. It shows that model is significant (i.e. $\mathrm{p}=$ .ooo) between dependent and independent variables in financial sector of Pakistan because all the $p$ value of variables are < .005. F-Statistics value (157.106) shows that variation of independent variables (Heuristics, day-to-day experience, risk aversion and corporate governance) is properly explain in dependent variables (Investment decision-making). The value is Durbin-Watson is 2.084 which less the 3.000. it means that regression model has not auto correlation problem because error term is independent. The estimated regression model is $I D M=1.104+b_{1} .145+b_{2} .201+b_{3} .120+b_{4}$ $.259+e$

\section{Discussion}

This study was conducted to investigate the factors which effect on the IDM in financial sector of Pakistan. Four hypotheses were developed on based existing literature to find out the hypothesized relationship between variables in Pakistani environment. According to the current study, institutional investors mostly use heuristics for IDM in financial sector of Pakistan. It is line with the past studies, (Hunter, 2011 and Waweru et al., 2008) tested the relationship between heuristics and IDM. Moreover, Gill, Khurshid, Mahmood, \& Ali (2018), reported that heuristics had the positive and significant impact on the IDM.

The result show that RA have the positive and significant effect on IDM in financial sector of Pakistan. RA play the important role in IDM in financial sector that identified in previous study. Almost investors are the risk averse and claim to be rational (Abani, Hary, Rious, \& Saguan, 2018). Investors' RA behavior affects the IDM of equity shareholders.

The present study shows that CG has the positive and significant effect on IDM in financial sector of Pakistan. According to Safdar A. Butt, (2012) reported that CG has the effect on institutional decision making so, these results reflect in current study. Schleich, Gassmann, Meissner, \& Faure (2019), indicated that good CG provides the high shareholder value Which get more intensions form institutional investors. 


\section{Conclusion}

The current study is mainly focus on identify the deviation in traditional trends of efficient market hypothesis due to behavioural finance. It explains the IDM of financial managers. This study shows the relationship of factors (Heuristics, DTDE, RA and CG) and IDM. The result of current study shows that these factors have the positive and significant effect on IDM in financial sector of Pakistan. Heuristics is more important factor which play the vital role in IDM in financial sector of Pakistan. The financial managers have to take risk according to policy of their organizations. According to present study, DTDE \& CG have the significant effect on IDM process. The overall response from the respondents shows that all the factors are contributed in IDM. It is observed based on current study that financial managers have not possess the uniformity in investing and trading behaviour additionality to stock market unpredictability. Furthermore, efficient market hypothesis deviation also observed.

\section{Reference}

Abani, A. O., Hary, N., Rious, V., \& Saguan, M. (2018). The impact of investors' risk aversion on the performances of capacity remuneration mechanisms. Energy policy, 112, 84-97.

Belmi, P., Neale, M. A., Reiff, D., \& Ulfe, R. (2020). The social advantage of miscalibrated individuals: The relationship between social class and overconfidence and its implications for class-based inequality. Journal of personality and social psychology, 118(2), 254.

Bolton, P., \& Roell, A. (2002). "European corporate governance: trading off liquidity against control", European Economic Review 43:1071-1083.

Brown, K. W., \& Ryan, R. M. (2003). The Benefits of Being Present: Mindfulness and Its Role in Psychological Well-Being. Journal of Personality and Social Psychology, 84(4), 822-848.

Cazilia \& Tahira, (2009). A comprehensive review of women in the U.S. economy. Investment in women, investment in America.

Gill, S., Khurshid, M. K., Mahmood, S., \& Ali, A. (2018). Factors effecting investment decision making behavior: The mediating role of information searches. European Online Journal of Natural and Social Sciences, 7(4), pp-758.

Haile, K. K., Nillesen, E., \& Tirivayi, N. (2020). Impact of formal climate risk transfer mechanisms on risk-aversion: Empirical evidence from rural Ethiopia. World Development, 130, 104930.

Hunter, J.E., \&Coggin, D.T. (2011). Analyst judgment: The efficient market hypothesis versus a psychological theory of human judgment. Organizational Behavior and Human Decision Processes, 42(3): 284-302.

Kahneman, D., \&Tversky, A. (1979). Prospect theory: An analysis of decision under risk.Econometrica, 47(2), 263-290.

Khalid, F. (2020). Factor Affecting Investment Behavior: Mediating Role of Self-Efficacy. Journal of Finance and Economics Research, 5(2), 112-125.

Klapper, L. F., \& Love, I. (2004). Corporate governance, investor protection, and performance in emerging markets. Journal of Corporate Finance, 10, 703-728.

Madaan, G., \& Singh, S. (2019). An analysis of behavioral biases in investment decision-making. International Journal of Financial Research, 10(4), 55-67.

Madaan, G., \& Singh, S. (2019). An analysis of behavioral biases in investment decision-making. International Journal of Financial Research, 10(4), 55-67.

Markowitz, H. (1958). Portfolio Selection. The Journal of Finance 7(1): 77-91.

Mayfield, C., Perdue, G., \& Wooten, K. (2008). Investment management and personality type. Financial Services Review, 17, 219-236.

Pasewark, W. R., \& Riley, M. E. (2010). It's a matter of principle: The role of personal values in 
investment decisions. Journal of Business Ethics, 93, 237-253.

Safdar A. Butt. (2012). Moderational effect of age on time pressure and human judgment-decision making relationship. Journal of Management \& Technology. ISSN 1997-4507.

Schleich, J., Gassmann, X., Meissner, T., \& Faure, C. (2019). A large-scale test of the effects of time discounting, risk aversion, loss aversion, and present bias on household adoption of energyefficient technologies. Energy Economics, 80, 377-393.

Shahid, M. S., \& Abbas, M. (2019). Does corporate governance play any role in investor confidence, corporate investment decisions relationship? Evidence from Pakistan and India. Journal of Economics and Business, 105, 105839.

Subrahmanyam, A. (2008). Social Network and Corporate Governance. Journal of European Financial Management, 14 (4): 633-662.Technology Journal, 2 (1).

Sun, C. (2020). Research on investment decision-making model from the perspective of "Internet of Things+ Big data”. Future generation computer systems, 107, 286-292.

Waweru, N. M., Munyoki, E. and Uliana, E., (2008). The effects of behavioural factors in investment decision-making: A survey of institutional investors operating at the Nairobi Stock Exchange, International of Journal Business and Emerging Markets, 1(1): pp. 24-41.

Zahera, S. A., \& Bansal, R. (2018). Do investors exhibit behavioral biases in investment decision making? A systematic review. Qualitative Research in Financial Markets. 